\title{
Response to Chia Siang Kow and colleagues
}

\author{
Angelo Avogaro $^{1}\left[\right.$ ] Benedetta Maria Bonora ${ }^{1} \cdot$ Gian Paolo Fadini ${ }^{1}$
}

Received: 30 September 2021 / Accepted: 3 October 2021 / Published online: 13 January 2022

(c) Springer-Verlag Italia S.r.l., part of Springer Nature 2022

We thank Chia Siang Kow and colleagues for their thoughtful considerations on our narrative review on diabetes treatment in patients with COVID-19 infection [1]. They point out that we did not include the sliding scale insulin treatment approach among the possible options for hospitalized patients. First of all, we fully agree that the inpatient blood glucose levels should also be considered when deciding the insulin regimen for hospitalized patients with diabetes. In our view, we also believe that sliding scale insulin can be a potential option for patients without significantly elevated blood glucose levels [2]. However, in most cases, the sliding scale insulin approach is performed by non-endocrinologists, who are not aware of the risks of the sliding scale approach, such as hyperglycemic episodes [3]. Although the hypoglycemic risk is slightly higher with the basal-bolus approach, this strategy is by far more physiological in terms of insulin concentrations and bioavailability. Moreover, we should anticipate rather than following hyperglycemia. Thus, we do not want to demonize the sliding scale approach, but this must be the exception and not the rule [4].

\section{Acknowledgements None.}

Author contributions $\mathrm{AA}, \mathrm{BMB}$, and GPF contributed to manuscript writing.

Funding None.

Managed By Massimo Porta.

This reply refers to the comment available online at https://doi.org/ 10.1007/s00592-021-01810-x.

Angelo Avogaro

angelo.avogaro@unipd.it

1 Department of Medicine, The University of Padova, Padua, Italy

\section{Declarations}

Conflict of interest BMB received lecture or advisory board fees from AstraZeneca, Boehringer Ingelheim, Eli Lilly, Mundipharma, Novartis, Novo Nordisk, and Sanofi. AA received research grants, lecture or advisory board fees from Merck Sharp and Dome, AstraZeneca, Novartis, Boehringer Ingelheim, Sanofi, Mediolanum, Janssen, Novo Nordisk, Lilly, Servier, and Takeda. GPF received grants, honoraria or lecture fees from Abbott, AstraZeneca, Boehringer, Lilly, Novo Nordisk, and Sanofi.

Ethical approval All human studies in the present review have been reviewed by the appropriate ethics committee and have therefore been performed in accordance with the ethical standards laid down in an appropriate version of the 1964 Declaration of Helsinki.

\section{References}

1. Avogaro A, Bonora B, Fadini GP (2021) Managing diabetes in diabetic patients with COVID: Where do we start from? Acta Diabetol. https://doi.org/10.1007/s00592-021-01739-1

2. Migdal AL, Fortin-Leung C, Pasquel F, Wang H, Peng L, Umpierrez GE (2021) Inpatient glycemic control with sliding scale insulin in noncritical patients with type 2 diabetes: Who can slide? J Hosp Med 16(8):462-468

3. Colunga-Lozano LE, Gonzalez Torres FJ, Delgado-Figueroa N et al (2018) Sliding scale insulin for non-critically ill hospitalized adults with diabetes mellitus. Cochrane Database Syst Rev 11(11):CD011296

4. Ambrus DB, O'Connor MJ (2019) Things we do for no reason: sliding-scale insulin as monotherapy for glycemic control in hospitalized patients. J Hosp Med 14(2):114-116. https://doi.org/10. 12788/jhm.3109

Publisher's Note Springer Nature remains neutral with regard to jurisdictional claims in published maps and institutional affiliations. 